other words, the reef will advance nineteen times as slowly as it does 560 metres from the shore, whilst the surface which is exposed to the dissolving effect of the sea-water has also increased nineteen-fold. Where an ocean-current strikes such an incline, no Globigerina ooze can be deposited on it, and here the dissolving action of sea-water will balance the accumulation of coral débris long before such a height-of 1000 metres-is attained. It is clear that as soon as such equilibrium is reached there is a limit to the further extension of the reef in that direction. On the opposite side, however, where ooze will accumulate and protect the advancing reef from solution, such advance would be possible, but on that side the growth of coral is notoriously slow. Certainly, when the foot of the reef has advanced to depths below the zone of protecting Globigerina ooze no further lateral growth in any direction will be possible, and on the whole I should not think that lateral growth can play any considerable part in the formation of great reefs. Only positive coastline shifting has such a result. In places where there is no such coast-line shifting (Gulf of Suez) the reefs are exceedingly small and insignificant.

Aithough therefore lateral growth no doubt does take place, it is not the actual cause of the formation of the great coral reefs.

We must, I think, revert to Darwin's subsidence theory, which is equally proved by the untenability of the hypothesis suggested for the purpose of superseding it, and by the direct evidence of the structure of the Triassic reefs in the Eastern Alps, which have actually attained their immense thickness during a period of positive shifting of the coast-line.

Innsbruck.

\section{Slugs and Thorns.}

In Nature, vol. xli. p. 393, I pointed out that thorns might not always be a protection from snails and slugs, since they were found in the stomach of a European slig, Parmacella. In further confirmation of this view, I have to-day dissected a number of sharp, straight, reddish-brown thorns, over a millimetre long, from the intestinal tract of Ariolimax niger, var, nov, macuiatus, a slug of rather doubtful affinities (possibly referable to $A$. andersoni), received from Dr. J. G. Cooper, who found it under drift-wood at Haywards, California. It is curious that the thorns do not pierce the intestine, but they appear to cause no inconvenience.

West Cliff, Colorado, April 2I.

\section{COMETS OF SHORT PERIOD.}

$\mathrm{I} \mathrm{T}$ is now generally accepted that the periodic comets of our system did not originate in it, but are bodies captured from outer space by one of the planets, the parabolic orbits in which they approached the system being transformed into elliptical ones. On account of the perturbing action of Jupiter, however, the orbits of shortperiod comets are liable to considerable modifications, and it is practically impossible to identify two apparitions of the same comet without laborious computations of the perturbations which it must have been subjected to between the two epochs. But even such computations may lead to a negative result, for frequently comets quite distinct have elements very much alike, probably because they are parts of an old comet travelling along the same orbit at greater or less intervals.

In some recent investigations on the capture theory of comets (Bulletin Astronomique, June and July I889), M. Tisserand developed a relation that might be employed to determine the possibility of identity of comets whose elliptical elements are known. This criterion depends upon the fact that the velocity of a body revolving round a central one is the same for equal radius-vectors. In the case of a comet having a parabolic orbit coming under the influence of a planet, the latter plays the part of the central body, and the relative velocity of the comet with reference to it will be the same at the point of entry into the sphere of attraction as at the point of departure from it, the one point being in the old orbit, the other in the new one. If two comets are identical, their velocities with reference to the perturbing planet will be the same at these points. ${ }^{1}$

M. L. Schulhof has discussed the possibility of identity of several comets by means of M. Tisserand's formula (Bull. Astr., November and December I 889, and Astr. Nach., 2964), and the following tables contain the values of $n$ found for those having periods from $3 \% 3$ to 8.8 years. In the first table, the comets whose periods are well known are given; in the second, those having uncertain periods. Comets which have undergone strong perturbations since discovery, and those for which perturbations prior to the first known apparition have been calculated, are given more than once, and the year indicated for which the elements are found. The symbols used have their usual signification, and $l$ is the longitude of the comet at the point of nearest approach to Jupiter.

\section{Comets of Known Period.}

Name of Comet.

$$
\underset{\pi}{\text { Elements of Orbit. }}
$$

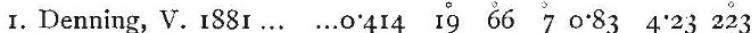



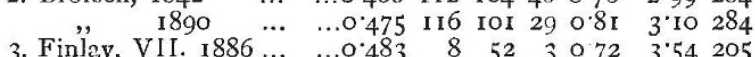

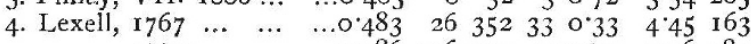
$\begin{array}{lllllllllllll}, & 1770 & \ldots & \ldots & \ldots 0 & 486 & 356 & 132 & 2 & 0.79 & 3.16 & 184\end{array}$

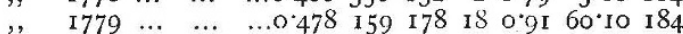

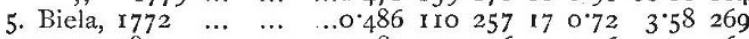

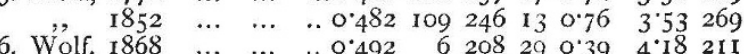

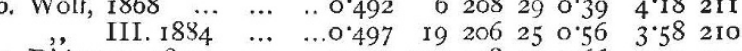

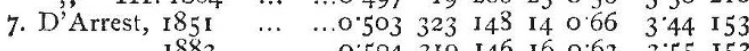

$\begin{array}{llllllllllllll} & 0 . & 1883 & \ldots & \ldots & 0.504 & 319 & 146 & 16 & 0.63 & 3.55 & \text { I53 }\end{array}$

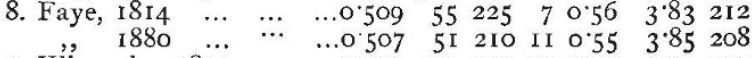

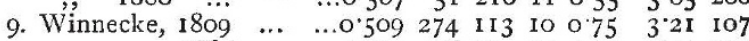

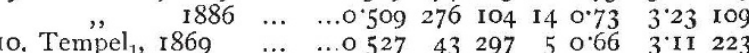

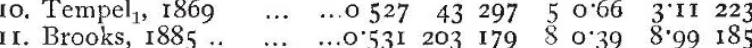

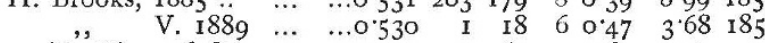


$\begin{array}{lllllllllll},, & \text { I. } 1844 & \ldots & \ldots 0.537 & 343 & 64 & 3 & 0.62 & 3.10 & 163\end{array}$ I3. Barnard, II. I884 … $\ldots .0 .556 \quad 306 \quad 5 \quad 50.58 \quad 3.08 \quad 126$

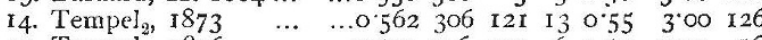

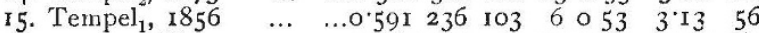

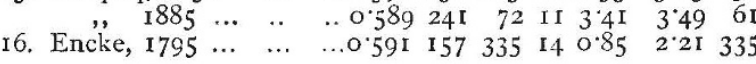

Comets of Uncertain Period.

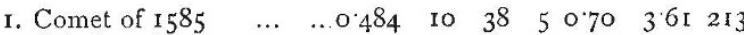

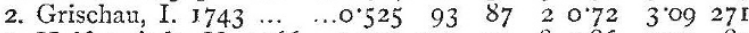

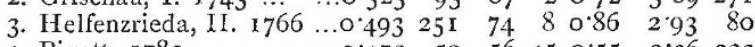

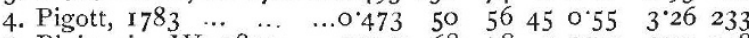

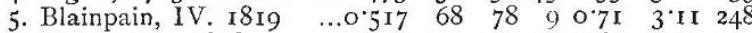
6. Tuttle, III. 1858 $\ldots \begin{array}{lllllllll} & \ldots .0 .527 & 201 & 1 & 75 & 20 & 0.67 & 3.52 & 357\end{array}$


8. Brooks, IV. 1886 $\ldots . . \ldots 0.553230 \quad 53$ I3 0.6 I 3.4 I 54

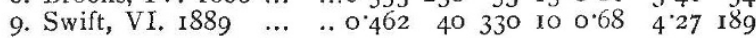

The value of $n$ therefore found by the formula given is almost constant for the 2 I known short-period comets, being contained within the limits 0.4r for Denning's comet, and 0.59 for Encke's and Tempel's comets.

It will also be seen that only five comets have their minimum distance to Jupiter's orbit between $l=284^{\circ}$ and $l=112^{\circ}$, while twelve have the point of nearest approach between $l=153^{\circ}$ and $l=233^{\circ}$. This unequal distribution along the ecliptic cannot be accidental, and

I M. Tisserand expressed the criterion very approximately by the formula-

$$
\frac{\mathrm{I}}{a_{1}}-\frac{x}{a_{2}}=\frac{2 \sqrt{ } \mathrm{A}}{\mathrm{R}^{2}}\left(\cos i_{2} \sqrt{ } p_{2}-\cos i_{1}\left(p_{1}\right),\right.
$$

where $\alpha_{1}, i_{2}, p_{1}, p_{2}, i_{1}, i_{2}$, are the semi-major axes, parameters, and inclinations of the old and new orbits; $A$ and $R$ the planet s semi-major axis and radius-vector at the point of nearest appr.ach. This relation may be divided up into two parts, having the form-

$$
n=\frac{\mathrm{I}}{a}+\frac{2 \sqrt{\mathrm{A}}}{\mathrm{K}} \cos i \sqrt{ } p \text {. }
$$

